\title{
Modified-release hydrocortisone decreases BMI and HbA1c in patients with primary and secondary adrenal insufficiency
}

\author{
Marcus Quinkler ${ }^{1,2}$, Roy Miodini Nilsen ${ }^{3}$, Kathrin Zopf ${ }^{2}$, Manfred Ventz ${ }^{2}$ \\ and Marianne Øksnes ${ }^{4,5}$ \\ ${ }^{1}$ Endocrinology in Charlottenburg, Stuttgarter Platz 1, 10627 Berlin, Germany, ${ }^{2}$ Clinical Endocrinology, \\ Charité Campus Mitte, Charité University Medicine Berlin, Berlin, Germany, ${ }^{3}$ Centre for Clinical Research, \\ Haukeland University Hospital, Bergen, Norway, ${ }^{4}$ Department of Clinical Science, University of Bergen, \\ Bergen, Norway and ${ }^{5}$ Department of Medicine, Haukeland University Hospital, Bergen, Norway
}

\author{
Correspondence \\ should be addressed \\ to M Quinkler \\ Email \\ marcusquinkler@t-online.de
}

\begin{abstract}
Objective: Patients with adrenal insufficiency (Al) have impaired health-related quality of life (HRQoL), which is thought to be in part due to unphysiological glucocorticoid replacement therapy. The aim was to compare once-daily hydrocortisone (HC) dual-release tablet (modified-release) with conventional HC therapy regarding clinical data and HRQoL.

Design and methods: We conducted an open, prospective trial at one endocrine center. There were 15 of 26 patients with primary Al, nine of 18 patients with secondary Al, and six congenital adrenal hyperplasia patients switched to modifiedrelease HC therapy by their own decision. We evaluated clinical outcome and disease-specific HRQoL by using AddiQoL questionnaire at baseline and at follow-up (median 202 days (85-498)).

Results: Patients on modified-release HC $(n=30)$ showed significant decreases in BMI $(26.0 \pm 0.75-25.6 \pm 0.71, P$ for change $=0.006)$ and $\mathrm{HbA} 1 \mathrm{c}(6.04 \pm 0.29-5.86 \pm 0.28, P$ for change $=0.005)$, whereas patients remaining on conventional $\mathrm{HC}$ $(n=20)$ showed no change in these parameters ( $P$ for interaction $=0.029$ and 0.017 respectively). No significant change in AddiQoL score were found in the modified-release HC group (83.8 baseline and 84.9 at follow-up; $P$ for change $=0.629$ ). In the conventional HC group, there was a significant decrease in scores $(84.0$ baseline and 80.9 at follow-up; $P$ for change $=0.016$ ), with a between-treatment $P$ for interaction of 0.066 . The fatigue subscore of AddiQoL showed the same pattern with a significant decrease $(P$ for change $=0.024)$ in patients on conventional $\mathrm{HC}$ therapy $(P$ for interaction $=0.116)$. Conclusions: Modified-release $\mathrm{HC}$ decreases $\mathrm{BMI}$ and $\mathrm{HbA} 1 \mathrm{C}$ compared with conventional $\mathrm{HC}$ treatment. In addition,
\end{abstract} it seems to stabilize HRQoL over time.

\section{Introduction}

A life-long, daily medical treatment with glucocorticoids is essential for patients with chronic adrenal insufficiency (AI). Hydrocortisone (HC) is thought to be the best glucocorticoid replacement therapy so far $(1,2)$. However, a major problem in clinical practice is the management of the total amount of daily HC substitution, the number and the optimal time point of daily doses. Too high HC doses result in supraphysiological blood cortisol levels, and doses too far apart may result in episodes with insufficient cortisol levels. This is thought to be one of several reasons of impaired health-related quality of life (HRQOL) seen in patients with AI $(3,4)$. Division or weight adaptation of the daily glucocorticoid dose into several single doses was postulated to improve cortisol profiles during the day and also well-being in small patient groups (5). However, up to now the current replacement strategies are still insufficient to fully restore well-being and daily performance $(4,6)$.

Published by Bioscientifica Ltd. 
Recently, a once-daily dual-release (modified release) HC tablet (Plenadren ${ }^{\circledR}$, Viropharma Inc.,Exton, PA, USA) has been introduced and shown a more physiological cortisol profile during daytime than conventional treatment in patients with primary AI (PAI) (7), but still lacking the ultradian physiological profile. This treatment proved to be safe and was well-tolerated during 24 consecutive months of therapy in patients with PAI (8). In the initial 3 months trial, this new modified release HC showed an improvement in cardiovascular risk factors, glucose metabolism, and HRQoL in comparison with conventional treatment with trice daily HC (7). However, more than $85 \%$ of the patients in the comparator group received daily HC doses of $25 \mathrm{mg}$ or more, more than $77 \%$ of patients even received $30 \mathrm{mg}$ or more. These daily doses are regarded nowadays as too high $(1,2)$, and are related to impaired HRQoL (6). The modified release HC therapy is thought to have a nearly $20 \%$ lower serum cortisol AUC than conventional therapy (7). This would result in the case of a switch from $30 \mathrm{mg}$ conventional $\mathrm{HC}$ therapy to $30 \mathrm{mg}$ of modified release $\mathrm{HC}$ and in an actual dose reduction to $24 \mathrm{mg}$ conventional HC. This indirect dose reduction might have resulted in the positive effects seen in the initial trial.

Therefore, the aim of our study was to detect possible differences in HRQoL in patients switched from conventional $\mathrm{HC}$ to modified release $\mathrm{HC}$ on an average daily HC dose of 20-22 mg. Secondly, up to now no reports have been published on patients with secondary AI (SAI) or with congenital adrenal hyperplasia (CAH) switched to modified release HC therapy.

\section{Subjects and methods}

\section{Study participants}

Between October 2012 and October 2013, patients with chronic PAI or SAI from the Endocrine Outpatient Clinic of the Charite University Medicine Berlin, who were on stable glucocorticoid replacement therapy for at least 6 months before entering the study, were asked to participate in the study. The patients were recruited in the order they appeared chronologically for their routine visit in the outpatient's clinic. Of the first 53 patients, three patients refused to participate $(5.7 \%)$. The remaining 50 patients were included into the study. The diagnosis was verified by review of the medical records. All patients had chronic AI with disease duration of at least 2 years. Patients under the age of 18 years, patients with AI due to long-term pharmacological glucocorticoid treatment, and patients with adrenocortical carcinoma were excluded.
The study was approved by the ethical committee of the Charité Campus Mitte Berlin (permit no. ES1/037/06), and written informed consent was obtained from all patients before participation. The study has therefore been performed in accordance with the ethical standards laid down in the 1964 Declaration of Helsinki. All patients had an emergency kit and a steroid emergency card and received special teaching regarding adrenal crisis.

A total of 50 patients with PAI and SAI were included into the study. The underlying cause of the 26 patients with PAI and the 18 patients with SAI is given in Table 1 . Six patients with CAH due to 21-hydroxylase deficiency agreed to participate in the study. The medical treatment of $\mathrm{CAH}$ was conventional HC and dexamethasone (DX) (Table 2). As those glucocorticoids have a different biological strength, dosage for DX was converted into milligrams of HC equivalent (DX 1-70 to HC) $(9,10)$. The fludrocortisone dose in PAI and CAH patients was not changed significantly during the treatment period (Table 2).

\section{Intervention}

Once-daily dual-release (modified release) HC (Plenadren ${ }^{\circledR}$, Viropharma) is available for the treatment of patients with AI in Germany since October 2012. In this study, patients were offered both treatment regimens (conventional HC or modified release HC) at baseline and they were free to choose which regimen they wanted to have (Fig. 1). Patients who decided to switch to once-daily HC dual-release tablet received the same daily dose of modified release $\mathrm{HC}$ as in their previous treatment (or respective equivalent for prednisolone). Recommendations were given to patients who switched to modified release HC including that the dual-release tablet should be taken in the fasting state early in the morning and that in the case of intercurrent illness the daily dose should be doubled (second dose $8 \mathrm{~h}$ after the first dose) or tripled ( 6 and $12 \mathrm{~h}$ after the first dose).

\section{Evaluations}

Baseline and follow-up evaluations consisted of physical examinations, a disease-specific health questionnaire, and a complete blood analysis $\left(\mathrm{Na}, \mathrm{K}, \mathrm{Ca}, \mathrm{PO}_{4}\right.$, creatinine, cholesterol, HDL- and LDL-cholesterol, triglycerides, and HbA1c) performed in the morning before $1000 \mathrm{~h}$. The follow-up visit was scheduled on the day the patient had the next visit at the outpatient clinic (usually every 3-9 months, on average 6 months). In the CAH cohort, we were able to assess questionnaires from a visit in 2011. 
Table 1 Age, duration of disease, underlying diagnosis, and hormone replacement therapy in 50 patients with primary and secondary Al.

\begin{tabular}{l}
\hline \\
\hline Primary Al ( $n$ ) \\
Age (years) median (range) \\
Duration of disease (years) median (range) \\
CAH \\
Cause of Al ( $n$ ) \\
Isolated Al \\
APS2 \\
With hypothyroidism \\
With diabetes mellitus type 1 \\
Bilateral adrenalectomy \\
Tuberculosis \\
CAH salt-wasting/simple-virilizing \\
DHEA replacement therapy \\
Secondary Al ( $n$ ) \\
Age (years) median (range) \\
Duration of disease (years) median (range) \\
Cause of Al ( $n$ ) \\
pituitary adenoma \\
Other tumors \\
Idiopathic insufficiency of the anterior pituitary \\
Sheehan's syndrome \\
Replacement therapy \\
L-thyroxine \\
Oral contraceptive \\
Estrogen replacement \\
Testosterone \\
Growth hormone \\
Desmopressin
\end{tabular}

\begin{tabular}{c}
\hline Modified release HC group \\
\hline 21 \\
$48.0(34,83)$ \\
$12.0(6,25)(n=15)$ \\
$43.0(34,54)(n=6)$ \\
2 \\
10 \\
7 \\
4 \\
3 \\
- \\
$4 / 2$ \\
3 \\
9 \\
$51.0(22,77)$ \\
$6.0(3,13)$ \\
5 \\
2 \\
1 \\
1 \\
9 \\
- \\
2 \\
3 \\
4 \\
2 \\
\end{tabular}

\begin{tabular}{c}
\hline Conventional HC group \\
\hline 11 \\
$54.0(35,73)$ \\
$13.0(2,31)$ \\
\\
4 \\
4 \\
4 \\
- \\
2 \\
1 \\
- \\
3 \\
9 \\
$54.0(33,76)$ \\
$10.0(5,27)$ \\
5 \\
3 \\
1 \\
- \\
9 \\
- \\
2 \\
4 \\
1 \\
3 \\
\end{tabular}

Al, adrenal insufficiency; APS, autoimmune polyglandular syndrome; $\mathrm{CAH}$, congenital adrenal hyperplasia; HC, hydrocortisone.

aBilateral adrenalectomy for Cushing's disease $(n=4)$ or bilateral pheochromocytoma $(n=1)$.

bother tumors: craniopharyngeoma $(n=3)$, sella turcica meningeoma $(n=1)$, and intracranial germ cell tumor $(n=1)$.

\section{Disease-specific health questionnaire}

To compare patients' complaints and fatigue over the treatment period with different glucocorticoid formulations, patients were asked to complete the newly developed Addison's disease-specific questionnaire (AddiQoL) $(11,12)$.

The recently developed AddiQoL for patients with PAI initially included 36 questions (11), and has been validated and reduced to a 30 item questionnaire (12). Items that are positive had scores from 1 to 6; negative HRQoL statements were reversed for questionnaire scoring (6 to 1 ). The scoring was converted to points: $6=4$ points; 5 and $4=3$ points; 3 and $2=2$ points, $1=1$ point. The algebraic sum of points was calculated. Higher points indicate a higher level of HRQoL. The subscale fatigue, which consists of questions 1-5 and 23, 26, and 27, was also calculated.

\section{Statistical analyses}

All analyses were performed by Stata/IC version 12.0 (Stata Corp., College Station, TX, USA) software for
Windows. To estimate change in AddiQoL and clinical outcomes from baseline to follow-up, we used linear regression models for repeated measures (i.e., linear mixed effects models). All models defined treatment, time, and treatment-by-time interaction as fixed effects, whereas a random intercept effect was specified to account for the intra-individual correlation. The intra-individual correlation was also directly modeled by using spatial power covariance structure to account for the unequal follow-up time, but this covariance structure did not improve model fit. Follow-up time was modeled as a 30-day incremental time variable and incorporated as continuous term in the regression models. A $P$ value for change within treatment groups was obtained directly from regression models by using the margins command (z-test) in Stata. To investigate between-treatment change in AddiQoL and clinical outcomes, we used the likelihood ratio test by comparing the log-likelihood between models with and without the treatment-by-time term. All analyses were adjusted for sex, type of AI, age, and age-by-time interaction. Additional 
Table 2 Patients with $\mathrm{Al}(n=50)$ at baseline and follow-up (234 \pm 132 days) after receiving modified release hydrocortisone or conventional hydrocortisone. Data are medians (min. and max.) or numbers.

\begin{tabular}{|c|c|c|c|c|}
\hline & \multicolumn{2}{|c|}{ Modified release HC group } & \multicolumn{2}{|c|}{ Conventional HC group } \\
\hline & Baseline & Follow-up & Baseline & Follow-up \\
\hline Female/male & \multicolumn{2}{|c|}{$23 / 7$} & \multicolumn{2}{|c|}{$14 / 6$} \\
\hline $\mathrm{PAI} / \mathrm{CAH} / \mathrm{SAI}$ & \multirow{2}{*}{\multicolumn{2}{|c|}{$\begin{array}{c}15 / 6 / 9 \\
48(22,83)\end{array}$}} & \multicolumn{2}{|c|}{$11 / 0 / 9$} \\
\hline Age (years) & & & & 76) \\
\hline \multicolumn{5}{|l|}{ PAI/SAI } \\
\hline HC daily dose (mg) & $20.0(15.0,30.0)(n=18)$ & $20.0(20.0,25.0)(n=24)$ & $20.0(10.0,70.0)$ & $20.0(12.5,50.0)$ \\
\hline Predni daily dose $(\mathrm{mg})$ & $5.0 \pm(4.0,5.0)(n=6)$ & - & - & - \\
\hline \multicolumn{5}{|l|}{$\mathrm{CAH}$} \\
\hline HC daily dose (mg) & $10.0(10.0,20.0)(n=4)$ & $20.0(20.0,25.0)(n=6)$ & & \\
\hline Dexa daily dose $(\mathrm{mg})$ & $0.25(0.19,0.38)(n=3)$ & - & & \\
\hline HC equivalent dose per day & $18.8(10.0,36.3)$ & $20.0(20.0,25.0)$ & & \\
\hline Fludrocortisone daily dose (mg) & $0.10(0.05,0.15)$ & $0.10(0.05,0.15)$ & $0.10(0.05,0.20)$ & $0.10(0.05,0.20)$ \\
\hline
\end{tabular}

PAl, primary adrenal insufficiency; $\mathrm{CAH}$, congenital adrenal hyperplasia; SAl, secondary adrenal insufficiency; HC, hydrocortisone; Predni, prednisolone. afor PAl and salt-wasting $\mathrm{CAH}$

adjustments were made for glucocorticoid dose and diabetes mellitus where appropriate. All $P$ values were two-sided and values $<0.05$ were considered statistically significant.

\section{Results}

At baseline, there were no differences regarding age (Table 2), BMI, HbA1c, or lipid profile between the two groups (modified release vs conventional HC) (Table 3). In both groups, the HC dose was diminished slightly but not significantly (Table 2). During the treatment period, there was a small but significant decrease in BMI in the modified release HC group ( $P$ for change 0.006 ) and no change in the HC group ( $P$ for change 0.887 ), with a significant between-treatment difference in BMI development during the treatment period $(P$ for interaction $=0.029)$ (Table 3$)$. In the modified release $\mathrm{HC}$ group, HbA1c decreased significantly ( $P$ for change 0.005 ), with a significant between-treatment difference in HbA1c development during treatment $(P$ for interaction $=0.017$ ). Also, there was a small decrease in total cholesterol in the modified release HC group ( $P$ for change $=0.036$ ), but without any between-treatment differences $(P$ for interaction $=0.294)$. No changes were found in either group for HDL, LDL, and triglycerides (Table 3 ), or for sodium, potassium, calcium, and 25-vitamin D3 (data not shown).

Median time of follow-up visit was 128 days (range 68-429) for the modified release HC group and 338 days (range 98-498) for the HC group, and after adjusting for potential confounding factors, the between-treatment difference in AddiQoL and Fatigue scores was not significant; $P$ for interaction $=0.066$ for AddiQoL and 0.116 for Fatigue scores (Table 3 ). In the modified release HC group $(n=30)$, we found no significant trend for change in AddiQoL and Fatigue scores. However, in the HC group, AddiQoL and Fatigue scores decreased significantly (AddiQoL, $P$ for trend $=0.016$ and Fatigue 0.024 ) (Table 3). This deterioration in HRQoL with conventional treatment showed the lowest scores in the patients with the longest follow-up time (Fig. 2).

When examining results by disease group, there were only small differences in scores between PAI and SAI. In the modified release HC group, patients with PAI $(n=15)$ had a mean AddiQoL score of 83.3 (10.8) at baseline and 85.5 (11.7) at follow-up, and Fatigue scores of 22.9 (4.3) and 22.7 (5.4) respectively. The nine SAI patients in the modified release HC group had mean AddiQoL score 84.2 (10.5) at baseline and 84.9 (10.5) at follow-up, and mean Fatigue score 20.9 (2.8) and 22.2 (3.2) respectively. In the HC group, patients with PAI $(n=11)$ had decreasing mean

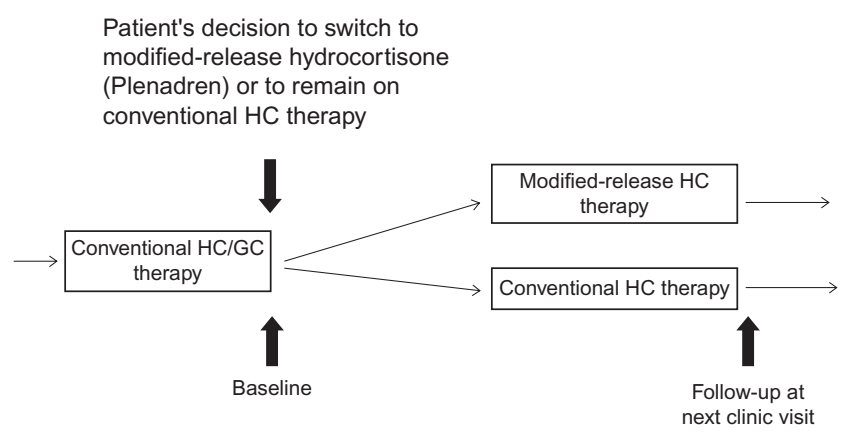

Figure 1

Study design. 
Table 3 AddiQoL scores and metabolic parameters in patients with adrenal insufficiency $(n=50)$ at baseline and follow-up after receiving modified release hydrocortisone or conventional hydrocortisone.

\begin{tabular}{|c|c|c|c|c|c|c|c|c|}
\hline \multirow[b]{2}{*}{ Outcome } & \multicolumn{2}{|c|}{ Baseline } & \multicolumn{2}{|c|}{ Follow-up } & \multicolumn{4}{|c|}{ Estimated change per 30 days $^{a}$} \\
\hline & $\begin{array}{c}\text { No. of } \\
\text { patients }\end{array}$ & $\begin{array}{c}\text { Observed } \\
\text { mean } \pm \text { s.E.M. }\end{array}$ & $\begin{array}{l}\text { No. of } \\
\text { patients }\end{array}$ & $\begin{array}{c}\text { Observed } \\
\text { mean } \pm \text { s.E.M. }\end{array}$ & $\beta \pm$ s.E.M. & $P$ change & $\begin{array}{l}\text { Adjusted } \\
\beta \pm \text { s.E.M. }\end{array}$ & $\begin{array}{l}\text { Adjusted } \\
\text { P change }\end{array}$ \\
\hline \multicolumn{9}{|l|}{ AddiQoL } \\
\hline Modified release $\mathrm{HC}$ & 30 & $83.8 \pm 1.81$ & 30 & $84.9 \pm 1.95$ & $0.157 \pm 0.167$ & 0.348 & $0.081 \pm 0.167$ & 0.629 \\
\hline $\begin{array}{l}\text { Conventional HC } \\
\text { interaction }^{c}\end{array}$ & 20 & $84.0 \pm 2.11$ & 20 & $80.9 \pm 2.50$ & $\begin{array}{c}-0.299 \pm 0.130 \\
0.031\end{array}$ & 0.021 & $\begin{array}{c}-0.305 \pm 0.127 \\
0.066\end{array}$ & 0.016 \\
\hline \multicolumn{9}{|l|}{ Fatigue } \\
\hline Modified release $\mathrm{HC}$ & 30 & $22.4 \pm 0.68$ & 30 & $22.6 \pm 0.81$ & $0.047 \pm 0.064$ & 0.464 & $0.017 \pm 0.064$ & 0.793 \\
\hline $\begin{array}{l}\text { Conventional HC } \\
\text { interaction }\end{array}$ & 20 & $21.1 \pm 0.66$ & 20 & $19.9 \pm 0.85$ & $\begin{array}{l}-0.108 \pm 0.050 \\
0.057\end{array}$ & 0.030 & $\begin{array}{l}-0.110 \pm 0.049 \\
0.116\end{array}$ & 0.024 \\
\hline \multicolumn{9}{|l|}{ BMI } \\
\hline Modified release $\mathrm{HC}$ & 30 & $26.0 \pm 0.75$ & 30 & $25.6 \pm 0.71$ & $-0.057 \pm 0.019$ & 0.003 & $-0.056 \pm 0.020^{d}$ & 0.006 \\
\hline $\begin{array}{l}\text { Conventional HC } \\
\text { interaction }^{c}\end{array}$ & 20 & $25.7 \pm 1.14$ & 20 & $25.8 \pm 1.08$ & $\begin{array}{l}0.002 \pm 0.015 \\
0.015\end{array}$ & 0.887 & $\begin{array}{l}0.000 \pm 0.015^{d} \\
0.029^{d}\end{array}$ & 0.985 \\
\hline \multicolumn{9}{|l|}{$\mathrm{HbA1c}$} \\
\hline Modified release $\mathrm{HC}$ & 27 & $6.04 \pm 0.29$ & 28 & $5.86 \pm 0.28$ & $-0.020 \pm 0.008$ & 0.014 & $-0.023 \pm 0.008^{\mathrm{e}}$ & 0.005 \\
\hline $\begin{array}{l}\text { Conventional HC } \\
\text { interaction }^{c}\end{array}$ & 20 & $5.63 \pm 0.13$ & 18 & $5.72 \pm 0.15$ & $\begin{array}{c}-0.0002 \pm 0.006 \\
0.049\end{array}$ & 0.975 & $\begin{array}{c}0.001 \pm 0.006^{\mathrm{e}} \\
0.017 \mathrm{e}\end{array}$ & 0.807 \\
\hline \multicolumn{9}{|l|}{ Cholesterol } \\
\hline Modified release $\mathrm{HC}$ & 30 & $213.8 \pm 7.97$ & 29 & $200.1 \pm 7.57$ & $-1.835 \pm 0.760$ & 0.016 & $-1.655 \pm 0.787$ & 0.036 \\
\hline $\begin{array}{l}\text { Conventional } \mathrm{HC} \\
\text { Interaction }\end{array}$ & 19 & $221.8 \pm 10.8$ & 19 & $210.9 \pm 13.1$ & $\begin{array}{c}-0.586 \pm 0.604 \\
0.198\end{array}$ & 0.332 & $\begin{array}{c}-0.605 \pm 0.608 \\
0.294\end{array}$ & 0.320 \\
\hline \multicolumn{9}{|l|}{ HDL } \\
\hline Modified release $\mathrm{HC}$ & 30 & $65.4 \pm 3.5$ & 29 & $62.7 \pm 3.3$ & $-0.302 \pm 0.231$ & 0.190 & $-0.317 \pm 0.240$ & 0.188 \\
\hline $\begin{array}{l}\text { Conventional HC } \\
\text { interaction }^{c}\end{array}$ & 19 & $62.5 \pm 4.3$ & 19 & $61.2 \pm 5.0$ & $\begin{array}{l}-0.187 \pm 0.183 \\
0.696\end{array}$ & 0.306 & $\begin{array}{l}-0.177 \pm 0.186 \\
0.647\end{array}$ & 0.340 \\
\hline \multicolumn{9}{|l|}{ LDL } \\
\hline Modified release $\mathrm{HC}$ & 30 & $127.2 \pm 7.6$ & 29 & $121.4 \pm 7.0$ & $-0.912 \pm 0.485$ & 0.060 & $-0.716 \pm 0.496$ & 0.149 \\
\hline $\begin{array}{l}\text { Conventional HC } \\
\text { interaction }^{c}\end{array}$ & 19 & $133.9 \pm 9.1$ & 18 & $128.4 \pm 11.1$ & $\begin{array}{c}0.037 \pm 0.388 \\
0.127\end{array}$ & 0.925 & $\begin{array}{c}0.010 \pm 0.385 \\
0.251\end{array}$ & 0.980 \\
\hline \multicolumn{9}{|l|}{ Triglycerides } \\
\hline Modified release $\mathrm{HC}$ & 30 & $115.7 \pm 11.9$ & 29 & $120.9 \pm 11.3$ & $0.944 \pm 1.828$ & 0.605 & $1.571 \pm 1.889$ & 0.406 \\
\hline $\begin{array}{l}\text { Conventional HC } \\
\text { interaction }^{c}\end{array}$ & 19 & $149.3 \pm 16.4$ & 19 & $173.4 \pm 26.7$ & $\begin{array}{l}0.333 \pm 1.462 \\
0.794\end{array}$ & 0.820 & $\begin{array}{c}0.376 \pm 1.471 \\
0.619\end{array}$ & 0.798 \\
\hline
\end{tabular}

Normal cholesterol, $<200 \mathrm{mg} / \mathrm{dl}(5.17 \mathrm{mmol} / \mathrm{l}) ;$ LDL-cholesterol, $<160 \mathrm{mg} / \mathrm{dl}(4.14 \mathrm{mmol} / \mathrm{l}) ; \mathrm{HDL}$-cholesterol, $>35 \mathrm{mg} / \mathrm{dl}(0.91 \mathrm{mmol} / \mathrm{l})$, triglycerides, and $<180 \mathrm{mg} / \mathrm{dl}(2.06 \mathrm{mmol} / \mathrm{l})$.

a By linear mixed effect models including a random intercept and the following fixed factors: treatment group, follow-up time, and treatment-by-time interaction. Follow-up time was transformed to time per 30 days and modeled as a continuous term.

${ }^{\mathrm{b}}$ Adjusted for sex, type of adrenal insufficiency, age, and age-by-time interaction.

'Overall $P$ value for treatment-by-time interaction ( $z$-test).

${ }^{\mathrm{d}}$ Additionally adjusted for glucocorticoid dose.

${ }^{\mathrm{e}}$ Additionally adjusted for diabetes mellitus.

AddiQoL score from 83.3 (10.2) at baseline to 80.1 (11.1) at follow-up, with mean Fatigue scores of 21.8 (3.1) and 20.2 (4.1) respectively. In the SAI HC group $(n=9)$, AddiQoL scores decreased from 85.0 (8.9) to 81.9 (11.9) and Fatigue scores from 20.3 (2.6) to 19.4 (3.5) from baseline to follow-up. For the six patients with $\mathrm{CAH}$, all included in the modified release HC group, mean AddiQoL score were 84.5 (s.D. 7.8) at baseline and 83.3 (9.7) at follow-up, and mean Fatigue scores 23.5 (s.D. 3.3) and 22.5 (4.2) respectively. Two years before baseline, these six patients had a mean AddiQoL score of 88.5 (s.D. 14.9) and Fatigue score of 23.3 (5.2), suggesting a gradual decline in HRQoL scores over time in this group.

Post hoc analysis without the six CAH patients showed the same pattern and did not substantially alter the results for the various outcome parameters compared with whole group analysis.

\section{Discussion}

Our study showed that modified-release HC decreases BMI and $\mathrm{HbA} 1 \mathrm{c}$ compared with conventional HC treatment. 


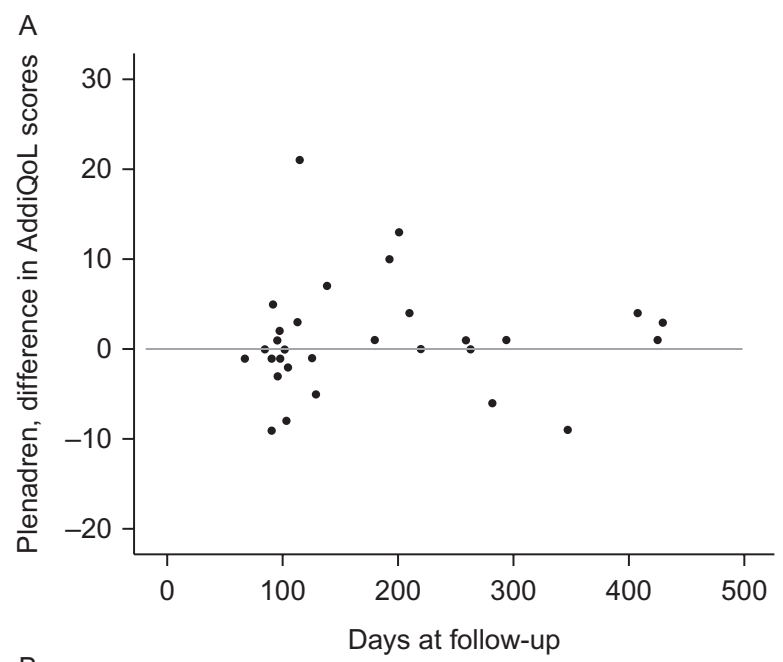

B

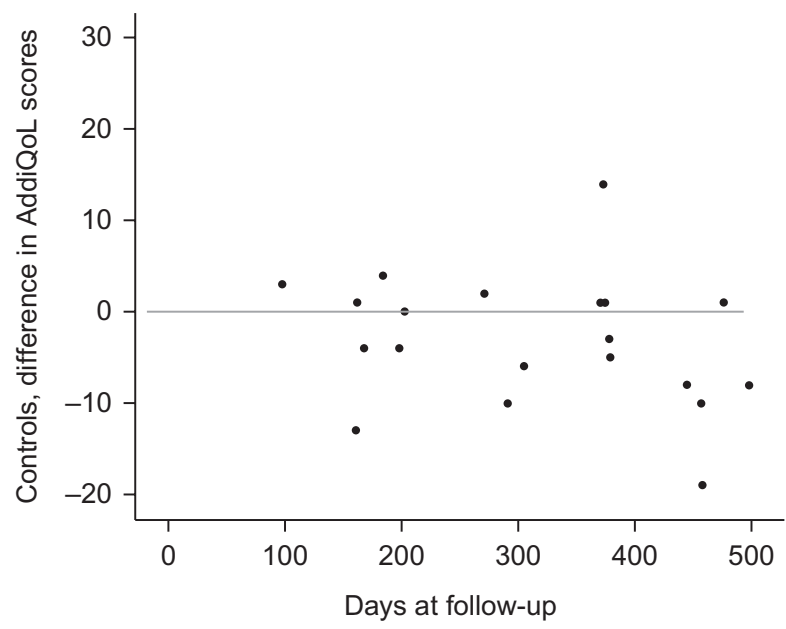

Figure 2

Scatter plots of differences in AddiQoL scores over follow-up time in patients on modified release hydrocortisone $(A)$ and conventional hydrocortisone (B). The differences in Fatigue scores showed a similar pattern (data not shown).

In a previous study, modified release HC treatment reduced 24-h glucocorticoid exposure by nearly $20 \%$, particularly in the afternoon, resulting in reduced body weight and $\mathrm{HbA1c}$ in a subgroup of patients with diabetes mellitus (7). In our study, HC equivalent doses were only slightly reduced in both treatment groups (although not statistically significant), and the mean $\mathrm{HC}$ daily dose in both treatment arms were lower (20-22 $\mathrm{mg}$ ) than that in previous studies. Because the modified release HC group included five diabetic patients and the HC group three, statistical results on $\mathrm{HbA1c}$ were adjusted for the presence of diabetes. Furthermore, because glucocorticoid dose has an impact on weight and BMI, results obtained for BMI were adjusted for daily dose. Nevertheless, modified release $\mathrm{HC}$ reduced both $\mathrm{BMI}$ and $\mathrm{HbA1c}$ significantly when compared with conventional treatment, although absolute changes were small. Plat et al. (13) have previously found that elevation of plasma cortisol in the evening when the hypothalamus-pituitary-adrenal (HPA) axis is normally quiescent has more deleterious metabolic effects than a similar elevation in the morning when the HPA axis is maximally activated. Possibly, the reduction in $\mathrm{HbA1c}$ levels results from reduced afternoon cortisol exposure with modified release HC. Accordingly, the reduction in 24-h $\mathrm{HC}$ exposure with modified release $\mathrm{HC}$ may explain the reduction in BMI.

Our study shows for the first time that differences in HRQoL using the disease-specific AddiQoL in patients with AI switched from conventional $\mathrm{HC}$ to modified release $\mathrm{HC}$ on an average daily $\mathrm{HC}$ dose of $20-22 \mathrm{mg}$ compared with patients remaining on conventional HC. Secondly, up to now this is the first report on patients with secondary AI or with CAH switched to modified release $\mathrm{HC}$ therapy. The underlying cause of reduced HRQoL in AI has yet to be elucidated. Some authors have suggested that the lack of DHEA could be a causative factor (14), although the largest placebo-controlled randomized study detected only minor HRQoL benefits of DHEA in AI (15). Another theory is that the autoimmune state in itself will compromise HRQoL, given that HRQoLs are affected in several autoimmune conditions $(16,17,18)$. A recent study in patients on thyroid replacement therapy has compared SF-36 scores between patient with autoimmune hypothyroidism and postoperative hypothyroidism, demonstrating lower scores in patients with anti-thyroid peroxidase antibodies (19), which supports this theory. Insufficient replacement therapy is suspected to be a major cause of reduced HRQoL in $\mathrm{AI}$, despite the fact that evidence has been lacking $(2,3)$. Therefore, efforts are being made to provide the most physiological cortisol replacement possible. There is a possible relation between daily dose and HRQoL, as too high dosage chronically could result in a slow decline in HRQoL scores over time, similar to the findings in mild Cushing's syndrome (20). Similarly, too low doses can lead to fatigue and a higher frequency of adrenal crisis, deteriorating HRQoL (21). A recent retrospective cross-sectional study in SAI patients has found that higher $\mathrm{HC}$ doses were associated with worse HRQoL, and that patients with doses lower than $10 \mathrm{mg} /$ day had the best HRQoL and patients receiving more than $25 \mathrm{mg}$ /day the poorest HRQoL (22). Another study found that AI patients with doses higher than $30 \mathrm{mg}$ /day have lower HRQoL levels than patients with 
lower doses (6). AI patients also have a higher risk of acquiring additional autoimmune disease over time, possibly with an impact on HRQoL levels, although studies on the impact of additional autoimmune disease have been inconsistent $(3,23)$.

In this study, we could not detect any HRQoL improvement with modified release $\mathrm{HC}$, possibly due to low numbers and low statistical power. Another possible explanation for the fact that HRQoL remained impaired might be that modified release $\mathrm{HC}$ is a nonphysiological glucocorticoid replacement in the hours before waking. However, we did find that HRQoL deteriorated with conventional treatment, with the lowest scores in the patients with the longest follow-up time, raising suspicion that HRQoL deteriorates over time in AI with conventional therapy. The largest HRQoL studies in AI have all been cross-sectional, and our results highlight the need for long-term HRQoL follow-up data regardless of replacement therapy strategy. Disease-specific HRQoL questionnaires can be more sensitive for detecting HRQoL changes over time in specific patient groups (24), but they should not be used in a normal population to provide $Z$-scores to take account of QoL deterioration with aging. Therefore, all statistical analyses in the current study were adjusted for sex, type of AI, age, and age-by-time interaction. The Addison's disease-specific AddiQoL questionnaire was previously applied in a large cross-sectional study, showing that HRQoL scores were lower in the oldest age groups (12), but the impact of AI duration was not investigated. This study was of short duration, and it is unlikely that the scores would deteriorate significantly because of the increasing age during the study.

In this study, no differences in scores were found between patients with isolated AI and patients with autoimmune polyglandular syndrome. Longitudinal data could possibly also provide clues to why HRQoL is reduced in Addison's disease, for instance by investigating the association between HRQoL change and dose, additional comorbidity, adrenal crisis frequency, antibody titer, etc.

There are limitations to this study, foremost the open nonrandomized design in which the patients themselves decided whether they wanted to change to modified release $\mathrm{HC}$ or to stay on conventional HC. Nonetheless, despite lack of randomization, there were only small differences in baseline characteristics between treatment groups and these were adjusted for in regression analyses. Furthermore, no treatment preference was presented to the patients by the physician. We can statistically correct for the lack of standardized study visit intervals. The low number of patients in each disease group increases the risk of type 2 error and makes it difficult to conclude on between-group differences in scores and AddiQoL validity in SAI and CAH. However, the strength of this study lies in the similarity to conventional clinical practice. A single group short-term clinical trial may not be completely representative for the broad spectrum of patients followed long term by most endocrinologists. In our field, most clinical trials present nonblinded short-term HRQoL data $(3,4,12,25)$, which may increase the risk of placebo effects. Presumably, long-term results are more important for the patients. We therefore believe that longitudinal HRQoL data are needed in AI.

In conclusion, we showed that modified release $\mathrm{HC}$ decreases BMI and HbA1c and seems to stabilize HRQoL, whereas conventional HC treatment seems to be accompanied by a decrease in HRQoL over time.

\section{Declaration of interest}

M Quinkler worked as a consultant for ViroPharma and had received honoraria for talks. M Øksnes, R M Nilsen, K Zopf, and M Ventz have nothing to disclose.

\section{Funding}

This research did not receive any specific grant from any funding agency in the public, commercial or not-for-profit sector.

\section{References}

1 Quinkler M \& Hahner S. What is the best long-term management strategy for patients with primary adrenal insufficiency? Clinical Endocrinology 201276 21-25. (doi:10.1111/j.1365-2265.2011.04103.x)

2 Grossman A, Johannsson G, Quinkler M \& Zelissen P. Therapy of endocrine disease: perspectives on the management of adrenal insufficiency: clinical insights from across Europe. European Journal of Endocrinology 2013169 R165-R175. (doi:10.1530/EJE-13-0450)

3 Hahner S, Loeffler M, Fassnacht M, Weismann D, Koschker AC, Quinkler M, Decker O, Arlt W \& Allolio B. Impaired subjective health status in 256 patients with adrenal insufficiency on standard therapy based on cross-sectional analysis. Journal of Clinical Endocrinology and Metabolism 200792 3912-3922. (doi:10.1210/jc.2007-0685)

4 Bleicken B, Hahner S, Loeffler M, Ventz M, Allolio B \& Quinkler M. Impaired subjective health status in chronic adrenal insufficiency: impact of different glucocorticoid replacement regimens. European Journal of Endocrinology 2008159 811-817. (doi:10.1530/EJE-08-0578)

5 Mah PM, Jenkins RC, Rostami-Hodjegan A, Newell-Price J, Doane A, Ibbotson V, Tucker GT \& Ross RJ. Weight-related dosing, timing and monitoring hydrocortisone replacement therapy in patients with adrenal insufficiency. Clinical Endocrinology 200461 367-375. (doi:10.1111/j.1365-2265.2004.02106.x)

6 Bleicken B, Hahner S, Loeffler M, Ventz M, Decker O, Allolio B \& Quinkler M. Influence of hydrocortisone dosage scheme on health-related quality of life in patients with adrenal insufficiency. Clinical Endocrinology 201072 297-304. (doi:10.1111/j.1365-2265.2009.03596.x)

7 Johannsson G, Nilsson AG, Bergthorsdottir R, Burman P, Dahlqvist P, Ekman B, Engstrom BE, Olsson T, Ragnarsson O, Ryberg $\mathrm{M}$ et al. 
Improved cortisol exposure-time profile and outcome in patients with adrenal insufficiency: a prospective randomized trial of a novel hydrocortisone dual-release formulation. Journal of Clinical Endocrinology and Metabolism 201297 473-481. (doi:10.1210/jc.2011-1926)

8 Nilsson AG, Marelli C, Fitts D, Bergthorsdottir R, Burman P, Dahlqvist P, Ekman B, Engstrom BE, Olsson T, Ragnarsson O et al. Prospective evaluation of long-term safety of dual-release hydrocortisone replacement administered once daily in patients with adrenal insufficiency. European Journal of Endocrinology 2014171 369-377. (doi:10.1530/EJE-14-0327)

9 Caldato MC, Fernandes VT \& Kater CE. One-year clinical evaluation of single morning dose prednisolone therapy for 21-hydroxylase deficiency. Arquivos Brasileiros de Endocrinologia e Metabologia 200448 705-712. (doi:10.1590/S0004-27302004000500017)

10 Rivkees SA \& Crawford JD. Dexamethasone treatment of virilizing congenital adrenal hyperplasia: the ability to achieve normal growth. Pediatrics 2000106 767-773. (doi:10.1542/peds.106.4.767)

11 Lovas K, Curran S, Oksnes M, Husebye ES, Huppert FA \& Chatterjee VK. Development of a disease-specific quality of life questionnaire in Addison's disease. Journal of Clinical Endocrinology and Metabolism 2010 95 545-551. (doi:10.1210/jc.2009-1711)

12 Oksnes M, Bensing S, Hulting AL, Kampe O, Hackemann A, Meyer G, Badenhoop K, Betterle C, Parolo A, Giordano R et al. Quality of life in European patients with Addison's disease: validity of the diseasespecific questionnaire AddiQoL. Journal of Clinical Endocrinology and Metabolism 201297 568-576. (doi:10.1210/jc.2011-1901)

13 Plat L, Leproult R, L'Hermite-Baleriaux M, Fery F, Mockel J, Polonsky KS $\&$ Van CE. Metabolic effects of short-term elevations of plasma cortisol are more pronounced in the evening than in the morning. Journal of Clinical Endocrinology and Metabolism 199984 3082-3092.

14 Arlt W, Callies F, van Vlijmen JC, Koehler I, Reincke M, Bidlingmaier M, Huebler D, Oettel M, Ernst M, Schulte HM et al. Dehydroepiandrosterone replacement in women with adrenal insufficiency. New England Journal of Medicine 1999341 1013-1020. (doi:10.1056/ NEJM199909303411401)

15 Gurnell EM, Hunt PJ, Curran SE, Conway CL, Pullenayegum EM, Huppert FA, Compston JE, Herbert J \& Chatterjee VK. Long-term DHEA replacement in primary adrenal insufficiency: a randomized, controlled trial. Journal of Clinical Endocrinology and Metabolism 200893 400-409. (doi:10.1210/jc.2007-1134)

16 Nicolucci A, Maione A, Franciosi M, Amoretti R, Busetto E, Capani F, Bruttomesso D, Di Bartolo BP, Girelli A, Leonetti F et al. Quality of life and treatment satisfaction in adults with type 1 diabetes: a comparison between continuous subcutaneous insulin infusion and multiple daily injections. Diabetic Medicine 200825 213-220. (doi:10.1111/ j.1464-5491.2007.02346.x)

17 Kvien TK, Kaasa S \& Smedstad LM. Performance of the Norwegian SF-36 Health Survey in patients with rheumatoid arthritis. II. A comparison of the SF-36 with disease-specific measures. Journal of Clinical Epidemiology 199851 1077-1086. (doi:10.1016/S0895-4356(98)00099-7)

18 Bianchi GP, Zaccheroni V, Solaroli E, Vescini F, Cerutti R, Zoli M \& Marchesini G. Health-related quality of life in patients with thyroid disorders. Quality of Life Research 200413 45-54. (doi:10.1023/B:QURE. 0000015315.35184.66)

19 Promberger R, Hermann M, Pallikunnel SJ, Seemann R, Meusel M \& Ott J. Quality of life after thyroid surgery in women with benign euthyroid goiter: influencing factors including Hashimoto's thyroiditis. American Journal of Surgery 2014207 974-979. (doi:10.1016/ j.amjsurg.2013.05.005)

20 Abraham SB, Abel BS, Rubino D, Nansel T, Ramsey S \& Nieman LK. A direct comparison of quality of life in obese and Cushing's syndrome patients. European Journal of Endocrinology 2013168 787-793. (doi:10.1530/EJE-12-1078)

21 Hahner S, Loeffler M, Bleicken B, Drechsler C, Milovanovic D, Fassnacht M, Ventz M, Quinkler M \& Allolio B. Epidemiology of adrenal crisis in chronic adrenal insufficiency - the need for new prevention strategies. European Journal of Endocrinology 2010162 597-602. (doi:10.1530/EJE-09-0884)

22 Ragnarsson O, Mattsson AF, Monson JP, Filipsson NH, Akerblad AC, Koltowska-Haggstrom M \& Johannsson G. The relationship between glucocorticoid replacement and quality of life in 2737 hypopituitary patients. European Journal of Endocrinology 2014171 571-579. (doi:10.1530/EJE-14-0397)

23 Erichsen MM, Lovas K, Skinningsrud B, Wolff AB, Undlien DE, Svartberg J, Fougner KJ, Berg TJ, Bollerslev J, Mella B et al. Clinical, immunological, and genetic features of autoimmune primary adrenal insufficiency: observations from a Norwegian registry. Journal of Clinical Endocrinology and Metabolism 200994 4882-4890. (doi:10.1210/ jc.2009-1368)

24 Prieto L, Santed R, Cobo E \& Alonso J. A new measure for assessing the health-related quality of life of patients with vertigo, dizziness or imbalance: the VDI questionnaire. Quality of Life Research 19998 131-139. (doi:10.1023/A:1026433113262)

25 Bleicken B, Hahner S, Ventz M \& Quinkler M. Delayed diagnosis of adrenal insufficiency is common: a cross-sectional study in 216 patients. American Journal of the Medical Sciences 2010339 525-531. (doi:10.1097/MAJ.0b013e3181d9f00b)

Received 14 December 2014

Revised version received 3 February 2015

Accepted 5 February 2015 